\title{
Vitamin D status in patients with rheumatoid arthritis: a correlation analysis with disease activity and progression, as well as serum IL-6 levels
}

\author{
Kinga Polasik ${ }^{1}$ Ewa Piotrowska ${ }^{1}$, Barbara Lipińska², Jacek M. Witkowski³ ${ }^{3}$ Ewa Bryl4 and \\ Stefan Tukaj ${ }^{\circledR}$
}

1Department of Molecular Biology, Faculty of Biology, University of Gdańsk, Gdańsk, Poland; 2Department of General and Medical Biochemistry, Faculty of Biology, University of Gdańsk, Gdańsk, Poland; ${ }^{3}$ Department of Pathophysiology, Medical University of Gdańsk, Gdańsk, Poland; ${ }^{4}$ Department of Pathology and Experimental Rheumatology, Medical University of Gdańsk, Gdańsk, Poland

\begin{abstract}
Objectives. Recent epidemiological studies suggested an association between a poor vitamin D [25(OH)D] status, inflammatory mediators, and rheumatoid arthritis (RA). We have recently proposed that pro-inflammatory interleukin 6 (IL-6) may represent a good marker for disease activity of RA. The aim of this study was to investigate the relationship between serum 25(OH)D levels and disease activity, joint damage, as well as serum IL-6 levels in a Polish RA population. Materials and Methods. Serum 25(OH)D levels were measured in 35 female RA patients and 38 age- and gender-matched healthy controls. Statistical correlations between 25(OH)D levels and the disease activity score 28 (DAS 28), joint damage based on the Steinbrocker criteria, as well as serum IL- 6 levels were performed. Results. There was no statistically significant difference between levels of $25(\mathrm{OH}) \mathrm{D}$ in RA $(16.89 \pm 8.57 \mathrm{ng} / \mathrm{ml})$ and healthy controls $(14.12 \pm 7.51 \mathrm{ng} / \mathrm{ml})$, and the vitamin $D$ deficiency $(<20 \mathrm{ng} / \mathrm{ml})$ was found in $71.43 \%$ of RA patients and $73.68 \%$ of healthy controls. While vitamin D status did not correlate with DAS $28(r=0.265, p=0.149)$ and joint damage based on the Steinbrocker criteria $(r=0.367$, $p=0.065)$, a positive correlation between 25(OH)D and IL-6 ( $\mathrm{r}=0.537, p=0.002)$ was observed in RA. Conclusion. Although further studies on a larger group of patients will be needed to confirm the data presented here, it seems that hypovitaminosis $D$ is common in the RA patients and middle-aged non-RA healthy women in the Polish population. 25(OH)D levels were similar in the RA patients and age- and gender-matched healthy controls, and were not associated with joint damage and disease activity in patients.
\end{abstract}

Key word: rheumatoid arthritis, vitamin D deficiency, 25(OH)D, IL-6

Received: 30 June, 2017; revised: 12 September, 2017; accepted: 13 September, 2017; available on-line: 05 December, 2017

e-mail: stefantukaj@gmail.com

Abbreviations: DMARDs, disease-modifying anti-rheumatic drugs; $25(\mathrm{OH}) \mathrm{D}$, non-active 25-hydroxyvitamin D; RA, Rheumatoid arthritis

\section{INTRODUCTION}

Rheumatoid arthritis (RA), a systemic autoimmune disease of the connective tissue, is characterized by inflammation of synovial joints that can lead to cartilage destruction and bone erosion (Jeffery et al., 2016). The etiology of the disease remains unclear, however, the interactions between genetic and environmental factors have been demonstrated in RA. The disease affects $0.3-$ $1.0 \%$ of the general population and is more prevalent among women and in developed countries (Chaudhari et al., 2016).

Although much progress has been made in revealing key players in pathophysiology of RA, its therapy remains challenging and in most cases still consists of conventional immunosuppressive treatment with corticosteroids and disease-modifying anti-rheumatic drugs (DMARDs) (Singh et al., 2016). The introduction of biological DMARDs, including IL-6 blocking agents, has led to improved management of RA, nevertheless, the economic costs associated with this disease are still high (Yusof \& Emery, 2013; Chaudhari et al., 2016).

There is an increasing interest in the role of vitamin $\mathrm{D}$ as a potential treatment for a number of inflammatory diseases (Jeffery et al., 2016). Vitamin D is a crucial secosteroid (pro)-hormone with a broad range of biological effects ranging from the classical role as a mediator of calcium and phosphorus metabolism promoting the healthy mineralization, growth and remodeling of the bone, to anti-microbial activity, and modulation of cellular differentiation (Hall \& Juckett, 2013). In addition, vitamin $\mathrm{D}$ exerts suppressive functions on cells of the adaptive immune response, i.e. those which are directly involved in the RA development (Alluno et al., 2015; Chaudhari et al., 2016; Jeffery et al., 2016).

The majority of vitamin D pool in the body $(\sim 90 \%)$ is endogenous. Upon UV radiation, pro-vitamin D is synthesized in the skin, and subsequently converted to nonactive 25-hydroxyvitamin D [25(OH)D] in the liver, and then to the active 1,25-dihydroxyvitamin $\mathrm{D}\left[1,25(\mathrm{OH})_{2} \mathrm{D}\right]$ in the kidney. Because $25(\mathrm{OH}) \mathrm{D}$ has a long half-life $(2-3$ weeks), it is the best serological biomarker for assessing the status of vitamin D in the body (Holick et al., 2011). Interestingly, several epidemiological studies demonstrated an association between a poor $25(\mathrm{OH}) \mathrm{D}$ status and RA, however studies contesting these observations are also found (Braun-Muscovici et al., 2011; Craig et al., 2010; Hong et al., 2014; Kostoglou-Athenassiou et al., 2012; Racovan et al., 2012; Rossini et al., 2010; Sahebari et al., 2014; Turhanoflu et al., 2011). Since the evidence from epidemiological studies concerning the relationship between serum $25(\mathrm{OH}) \mathrm{D}$ concentrations and RA is inconsistent (Jeffery et al., 2016; Lin et al., 2016), the aim of this study was to verify this assumption by assessing patients from northern Poland. 
Table 1. General characteristics of RA patients.

\begin{tabular}{lc}
\hline & $R A(n=35)$ \\
\hline Disease duration (years) & $8.92 \pm 8.75$ \\
\hline Disease activity score (DAS 28) & $4.18 \pm 1.01$ \\
\hline Steinbrocker's criteria (stage) & \\
\hline I & $n=5$ \\
II & $n=6$ \\
III & $n=2$ \\
undefined & $n=13$ \\
\hline
\end{tabular}

\section{MATERIALS AND METHODS}

Patients and controls. Thirty-five female patients with RA (mean age $47.54 \pm 14.78$ ) fulfilling ACR criteria for the classification of rheumatoid arthritis and 38 female healthy controls (mean age $51.66 \pm 6.79$ ) were included in this study. The disease activity was assessed according to the Disease Activity Score including 28 joint counts (DAS 28-ESR=DAS 28), and joint damage was evaluated based on the Steinbrocker radiographic criteria (I-IV). Selected characteristics of the RA patients are presented in Table 1. Serum samples of the patients were collected throughout the whole year and some insignificant fluctuations in the $25(\mathrm{OH}) \mathrm{D}$ levels over a specific period of a year have been observed (Supplementary Data 1 at www.actabp.pl). The use of human biological material was approved by the Ethics Committee of the Medical University of Gdańsk, Poland, and written informed consent was obtained according to the Declaration of Helsinki.

Detection of serum 25(OH)D. Serum levels of vitamin $\mathrm{D}$ were measured by a $25(\mathrm{OH})$ vitamin D ELISA kit (Sigma-Aldrich) according to the manufacturer's instructions.

Cytokine measurements. Serum levels of IL-6 were measured by a flow cytometric bead array (Becton Dickinson).

Statistical analysis. All statistical analyses were performed using GraphPad Prism 5 (San Diego, California). The Shapiro-Wilk test was used to verify whether the data had normal distribution. Non-normal distributed data was analyzed by Mann Whitney U test and Spearman's rank correlation test. $P$ values less than 0.05 were considered as significant.

\section{RESULTS}

\section{Inadequate serum levels of vitamin $\mathrm{D}$ are common in the RA patients and healthy controls}

In this study, we examined serum levels of the major circulating form of vitamin $\mathrm{D}-25(\mathrm{OH}) \mathrm{D}$ in the RA patients, as well as age- and gender-matched healthy controls in the Polish population. The mean serum level of $25(\mathrm{OH}) \mathrm{D}$ in the RA patients was not significantly different from that of the controls $(16.89 \pm 8.57 \mathrm{ng} / \mathrm{ml}$ vs. $14.12 \pm 7.51 \mathrm{ng} / \mathrm{ml}$, respectively; $P=0.13$ ) (Fig. 1). Vita-

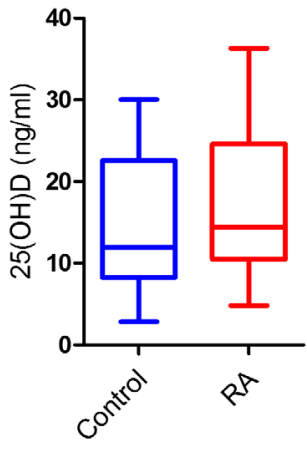

Figure 1. Vitamin D status in patients with rheumatoid arthritis is similar to that of healthy controls.

Serum levels of 25-hydroxyvitamin D $[25(\mathrm{OH}) \mathrm{D}]$ in rheumatoid arthritis (RA) patients $(n=35)$ and age- and gender-matched healthy controls $(n=38)$, measured by ELISA. The box-plot presents the median value, the inter-quartile range and the Min-Max values.

min D deficiency $(<20 \mathrm{ng} / \mathrm{ml})$ and insufficiency (21-29 $\mathrm{ng} / \mathrm{ml})$ were found in $71.43 \%(\mathrm{n}=25)$ and $17.14 \%(\mathrm{n}=6)$ of the RA patients and $73.68 \%(\mathrm{n}=28)$ and $23.68 \%$ $(n=9)$ of the healthy controls, respectively.

\section{Vitamin D status does not correlate with disease activity and joint damage in RA}

There was no significant relationships between the vitamin D levels and DAS $28 \quad(\mathrm{r}=0.265, \quad p=0.149)$ (Fig. 2A), as well as joint damage based on the Steinbrocker criteria $(r=0.367, p=0.065)$ in the RA patients (Fig. 2B). The lack of significant differences in the above-mentioned analysis has been confirmed by using one-way ANOVA test (Supplementary data 1). We found, however, that levels of serum IL-6 positively correlated $(\mathrm{r}=0.537, p=0.002)$ with the levels of $25(\mathrm{OH}) \mathrm{D}$

A

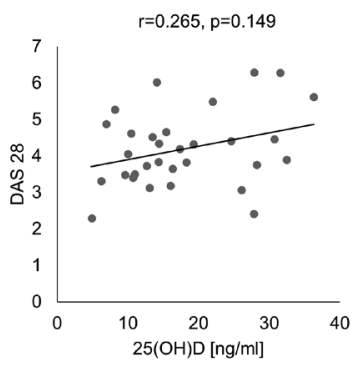

C

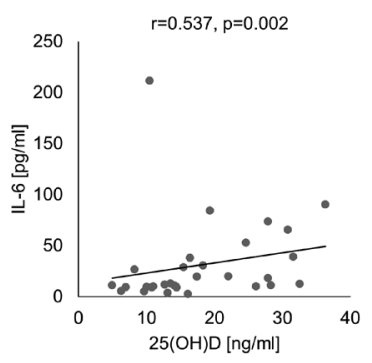

Figure 2. Vitamin D status is not associated with disease activity and joint damage in RA patients.

Analysis of a relationship between levels of 25-hydroxyvitamin $D$ $[25(\mathrm{OH}) \mathrm{D}]$ and disease activity score 28 (DAS 28) (A), joint damage based on the Steinbrocker radiographic criteria (B), as well as serum IL-6 levels $(\mathbf{C})$ in the RA patients. 
in the RA patients (Fig. 2C). There was no such correlation in a control group $(\mathrm{r}=-0.044, p=0.792)$.

\section{DISCUSSION}

Previous studies have demonstrated that vitamin $\mathrm{D}$ deficiency can impair immune function, resulting in an increased prevalence of autoimmune diseases such as multiple sclerosis, type 1 diabetes mellitus, and systemic lupus erythematosus (Yang et al., 2013). Vitamin D deficiency has been also implicated in the pathogenesis of RA, a systemic autoimmune disease of the connective tissue characterized by inflammation of synovial joints (Jeffery et al., 2016). Our results suggest that the vitamin D status is generally not altered in patients with RA in northern Poland when compared with age- and gender-matched healthy individuals $(16.89 \pm 8.57 \mathrm{ng} / \mathrm{ml}$ vs. $14.12 \pm 7.51 \mathrm{ng} /$ $\mathrm{ml}$, respectively). Our findings are consistent with regard to the level of vitamin D in other cohorts of patients with RA. For instance, Kostoglou-Athanassiou and coworkers (2012) and Hong and coworkers (2014) found that the mean serum levels of $25(\mathrm{OH}) \mathrm{D}$ in the RA patients were $15.26 \mathrm{ng} / \mathrm{ml}$ and $17.25 \mathrm{ng} / \mathrm{ml}$, respectively. Both authors, however, observed that the mean levels of vitamin $\mathrm{D}$ were significantly lower in the RA groups than in respective controls (Hong et al. 2014; Kostoglou-Athanassiou et al. 2012). This discrepancy might be due to the difference in the level of vitamin D in populations of healthy people inhabiting different latitudes and the fact that in Poland vitamin D deficiency is observed in most of the healthy people (Kmieć et al., 2014, 2015; Płudowski et al., 2016). Recent epidemiological study based on 5775 adult volunteers in the general Polish population revealed that the mean $25(\mathrm{OH}) \mathrm{D}$ concentration in the studied population was $18.0 \pm 9.6 \mathrm{ng} / \mathrm{ml}$ (Płudowski et al., 2016). Another study based on 448 healthy volunteers from northern Poland showed that the mean level of vitamin $D$ was $14.3 \pm 6.6 \mathrm{ng} / \mathrm{ml}$ (Kmieć et al., 2014), and was significantly dependent on seasonal sun exposure in a follow-up study (Kmieć et al., 2015). It has been generally accepted that $25(\mathrm{OH}) \mathrm{D}$ serum concentration below $20 \mathrm{ng} / \mathrm{ml}$ should be defined as vitamin D deficiency (Holick et al., 2011). Here, vitamin D deficiency $(<20 \mathrm{ng} / \mathrm{ml})$ was found in the majority of both, the RA patients $(71.43 \%)$ and healthy controls $(73.68 \%)$. Our results are consistent with the findings of the previous study since vitamin D deficiency was found in $76.3 \%$ of RA patients from central part of Poland and in $84.4 \%$ of healthy adults from northern Poland (Kmieć et al., 2014; Raczkiewicz et al., 2015). Several studies have found inverse association between inadequate vitamin $\mathrm{D}$ status and disease activity in RA (Cutolo et al., 2006; Haque et al., 2010; Hong et al., 2014; Kerr et al., 2011; Kostoglou-Athenassiou et al., 2012; Raczkiewicz et al., 2015; Turhanoflu et al., 2011; Welsh et al., 2011). There are also reports indicating negative correlations between vitamin $\mathrm{D}$ levels and pro-inflammatory cytokines, including TNF- $\alpha$, IL-1 $\beta$, IL-17, as well as IL-6 in RA (Mateen et al., 2017). By contrast, no correlations between vitamin D deficiency and disease activity in RA have been reported by other authors (Baker et al., 2012; Braun-Muscovici et al., 2011; Craig et al., 2010; Racovan et al., 2012; Rossini et al., 2010; Sahebari et al., 2014). In this study, no significant relationships were found between vitamin $D$ levels and either disease activity and joint damage based on the Steinbrocker radiographic criteria in the RA patients. We have recently found that in the RA patients, the serum levels of pro-inflammatory IL-6 were significantly elevated (about 7-fold compared to healthy control) and positively correlated with disease activity and joint damage based on the Steinbrocker criteria (Tukaj et al., 2010). In the study presented here, a positive correlation between the vitamin D status and IL-6 levels has been observed in the RA patients. It is unclear why the results of our study differ from those obtained by Mateen and coworkers (2017). In addition to the different cohorts living in distinct geographical latitudes, the heterogeneity in disease activity and therapeutic status may have contributed to these discrepant outcomes. This unexpected observation indicates that the mechanisms of the role of vitamin $\mathrm{D}$ in expression of IL-6 are not completely elucidated. Naghavi and coworkers (2015), for instance, had found that vitamin D supplementation of patients with multiple sclerosis led to a significant up-regulation of IL-6 in peripheral blood mononuclear cells (PBMCs). We hypothesize that higher levels of pro-inflammatory IL-6 in patients with RA may stimulate the synthesis of $25(\mathrm{OH}) \mathrm{D}$ as a counterbalancing mechanism for inflammatory niche and the non-exclusive explanation for this assumption might be supported by the fact that UVB radiation, being the key factor for cholecalciferol (vitamin $\mathrm{D}_{3}$ ) synthesis in the skin, may also trigger cutaneous inflammatory response mediated by induction of IL-6 expression in an IL- $1 \alpha$-depended way (Chung et al., 1996). The presence of such correlation, as well as lack of correlations between vitamin $\mathrm{D}$ and disease progression or activity, do not simply reflect the hypothesis of the contribution of hypovitaminosis D in RA. While the link between IL-6 and RA is quite well established (Yusof \& Emery, 2013), the impact of vitamin D deficiency on disease activity, joint damage, and soluble inflammatory mediators remains in need of further elucidation. The essential question arises whether poor $25(\mathrm{OH})$ $\mathrm{D}$ status is a cause or consequence of the RA development. Further, it is still unclear whether the association of vitamin $\mathrm{D}$ deficiency with $\mathrm{RA}$ severity, observed in some studies, supports the hypothesis of a role for vitamin D in the initiation or rather progression of the disease. To address this question, further analyses in prospective vitamin $\mathrm{D}$ supplementation trials are required. Future studies on a larger and better characterized group of patients (e.g. information on vitamin $\mathrm{D}$ supplementation, sun exposition or treatment) are needed to confirm the data presented here and to further clarify whether RA progression and/ or activity is related to the vitamin D status.

\section{CONCLUSIONS}

Our results suggest that the vitamin D status is generally not altered in Polish patients with RA when compared with age- and gender-matched healthy controls. The levels of $25(\mathrm{OH}) \mathrm{D}$ examined in both, the RA and non-RA adults showed that a majority of the Polish population are vitamin $\mathrm{D}$ deficient. The lack of associations between the vitamin $\mathrm{D}$ levels and disease activity or progression, as well as presence of a positive correlation between $25(\mathrm{OH}) \mathrm{D}$ and IL-6 levels in patients suggest the need to verify the hypothesis of vitamin $\mathrm{D}$ involvement in RA.

\section{Conflict of interest}

The authors state no conflict of interest.

\section{Acknowledgements}

This study was supported by the Polish National Science Centre (NCN) (2014/13/D/NZ6/02147). 


\section{LITERATURE}

Alluno A, Manetti M, Caterbi S, Ibba-Manneschi L, Bistoni O, Bartoloni E, Valentini V, Terenzi R, Gerli R (2015) Altered immunoregulation In rheumatoid arthritis: the role of regulatory $\mathrm{T}$ cells and proinflammatory Th17 cells and therapeutic implication. Mediators Inflamm 751793. http://doi.org/10.1155/2015/751793

Baker J, Baker D, Toedter G, Shults J, Von Feldt J, Leonard M (2012) Associations between vitamin $\mathrm{D}$, disease activity and clinical response to therapy in rheumatoid arthritis. Clin Exp Rheumatol 30: 658-664

Braun-Muscovici Y, Toledano K, Markovits D, Rozin A, Nahir A, Balbir-Gurman A (2011) Vitamin D level: is it related to disease activity In inflammatory joint disease? Rheumatol Int 31: 493-499. http:// doi.org/10.1007/s00296-009-1251-6

Chaudhari K, Rizvi S, Syed BA (2016) Rheumathoid arthritis: current and future trends. Nat Rev Drug Discov 15: 305-306. http://doi. org/10.1038/nrd.2016.21

Chung JH, Youn SH, Koh WS, Eun HC, Cho KH, Park KC, Youn JI (1996) Ultraviolet B irradiation-enhanced interleukin (IL)-6 production and mRNA expression are mediated by IL-1 alpha in cultured human keratinocytes. J Invest Dermatol 106: 715-720

Craig S, Yu F, Curtis J, Alarcón G, Conn D, Jonas B, Callahan LF, Smith EA, Moreland LW, Bridges SL, Jr, Mikuls TR (2010)Vitamin D status and its associations with disease activity and severity in African Americans with recent-onset rheumatoid arthritis. J Rheumatol 37: 275-281. http://doi.org/10.3899/jrheum.090705

Cutolo M, Otsa K, Laas K, Yprus M, Lethme R, Secchi M, Sulli A, Paolino S, Seriolo B (2006) Circannual vitamin D serum levels and disease activity in rheumatoid arthritis: Northern versus Southern Europe. Clin Exp Rheumatol 24: 702-704

Hall AC, Juckett MB (2013) The role of vitamin D in hematologic disease and stem cell transplantation. Nutrients 5: 2206-2221. http:// doi.org/10.3390/nu5062206

Haque U, Barlett S (2010) Relationships among vitamin D, disease activity, pain and disability in rheumatoid arthritis. Clin Exp Rheumatol 28: $745-747$

Holick MF, Binkley NC, Bischoff-Ferrari HA, Gordon CM, Hanley DA, Heaney RP, Murad MH, Weaver CM (2011) Evaluation, treatment and orevention of vitamin D deficiency: an endocrine society clinical practice guideline. J Clin Endocrinol Metab 96: 1911-1930. http://doi.org/10.1210/jc.2011-0385

Hong Q, Xu J, Xu S, Lian L, Zhang M, Ding C (2014) Associations between serum 25-hydroxyvitamin $\mathrm{D}$ and disease activity, inflammatory cytokines and bone loss in patients with rheumatoid arthritis. Rheumatology (Oxford) 53: 1994-2001. http://doi.org/10.1093/rheumatology/keu173

Jeffery LE, Raza K, Hewison M (2016) Vitamin D in rheumathoid arthritis-towards clinical application. Nat Rev Rheumatol 12: 201-210. http://doi.org/10.1038/nrrheum.2015.140

Kerr G, Sabahi I, Richard J, Caplan L, Cannon G, Reimold A, Thiele GM, Jonhson D, Mikuls TR (2011) Prevalence of vitamin D insufficiency/deficiency in rheumatoid arthritis and association with disease severity and activity. I Rheumatol 38: 53-59

Kmieć P, Żmijewski M, Waszak P, Sworczak K, Lizakowska-Kmieć M (2014) Vitamin D deficiency during winter months among an adult, predominantly urban, population in Northern Poland. Endokrynol Pol 65: 105-13. http://doi.org/10.5603/EP.2014.0015

Kmieć P, Żmijewski M, Lizakowska-Kmieć M, Sworczak K (2015) Widespread vitamin D deficiency among adults from northern Poland $\left(54^{\circ} \mathrm{N}\right)$ after months of low and high natural UVB radiation. Endokrynol Pol 66: 30-8. http://doi.org/10.5603/EP.2015.0006

Kostoglou-Athenassiou I, Athanassiou P, Lyraki A, Raftakis I, Antoniadis C (2012) Vitamin D and rheumatoid arthritis. Ther Adv Endocrinol Metab 3: 181-187. http://doi.org/10.5604/17322693.1165194
Lin J, Liu J, Davies ML, Chen W (2016) Serum vitamin d level and rheumatoid arthritis disease activity: review and meta-analysis. PLOS One 11: e0146351. http://doi.org/10.1371/journal.pone.0146351

Mateen S, Moin S, Shahzad S, Khan A (2017) Level of inflammatory cytokines in rheumatoid arthritis patients: Correlation with 25-hydroxy vitamin D and reactive oxygen species. PLoS One 12: e0178879. http://doi.org/10.1371/journal.pone.0178879

Płudowski P, Ducki C, Konstantynowicz J, Jaworski M (2016) Vitamin D status in Poland. Pol Arch Med Wewn 126: 530-539. http://doi. org/10.20452/pamw.3479

Naghavi Gargari B, Behmanesh M, Shirvani Farsani Z, Pahlevan Kakhki M, Azimi AR (2015) Vitamin D supplementation up-regulates IL-6 and IL-17A gene expression in multiple sclerosis patients. Int Immunopharmacol 28: 414-419. http://doi.org/10.1016/j. intimp.2015.06.033

Racovan M, Walitt B, Collins CE, Pettinger M, Parks CG, Shikany JM, Wactawski-Wende J, Manson JE, Moreland L, Wright N, Jackson $\mathrm{R}$, Howard BV (2012) Calcium and vitamin D supplementation and incident rheumatoid arthritis: the women's health initiative calcium plus vitamin D trial. Rheumatol Int 32: 3823-3830. http://doi. org/10.1007/s00296-011-2268-1

Raczkiewicz A, Kisiel B, Kulig M, Tłustochowicz W (2015) Vitamin $\mathrm{D}$ status and its association with quality of life, physical activity, and disease activity in rheumatoid arthritis patients. J Clin Rheumatol 21: 126-130. http://doi.org/10.1097/RHU.0000000000000233

Rossini M, Maddali BS, La Montagna G, Minisola G, Malavolta N, Bernini L, Cacace E, Sinigaglia L, Di Munno O, Adami S (2010) Vitamin D deficiency In rheumatoid arthritis: prevalence, determinants and associations with disease activity and disability. Arthritis Res Ther 12: R216. http://doi.org/10.1186/ar3195

Sahebari M, Mirfeizi Z, Rezaieyazdi Z, Rafafpanah H, Goshyeshi L (2014) $1,25(\mathrm{OH})$ vitamin D serum values and rheumatoid arthritis disease activity. Caspian J Intern Med 5: 148-155

Singh JA, Saag KG, Bridges SL, Akl EA, Bannuru RR, Sullivan MC, Vaysbrot E, McNaughton C, Osani M, Shmerling RH, Curtis JR, Furst DE, Parks D, Kavanaugh A, O’Dell J, King C, Leong A, Matteson EL, Schousboe JT, Drevlow B, Ginsberg S, Grober J, St Clair EW, Tindall E, Miller AS, McAlindon T (2016) 2015 American college of rheumatology guideline for the treatment of rheumatoid arthritis. Arthritis Rheumatol 68: 1-26. http://doi.org/10.1002/ art. 39480

Tukaj S, Kotlarz A, Jóźwik A, Smoleńska Z, Bryl E, Witkowski JM, Lipińska B (2010). Cytokines of the Th1 and Th2 type in sera of rheumatoid arthritis patients; correlations with anti-Hsp40 immune response and diagnostic markers. Acta Biochim Pol 57: 327-332

Turhanoflu AD, Güler H, Yönden Z, Aslan F, Mansuroglu A, Ozer C (2011) The relationship between vitamin D and disease activity and functional health status in rheumatoid arthritis. Rheumatol Int 31: 911-914. http://doi.org/10.1007/s00296-010-1393-6

Welsh P, Peters M, McInnes I, Lems W, Lips P, McKellar G, Knox S, Wallace AM, Dijkmans BAC, Nurmohamed MT, Sattar N (2011) Vitamin D deficiency is common in patients with RA and linked to disease activity, but circulating levels are unaeffects by TNF $\alpha$ blockade: results from a prospective cohort study. Ann Rheum Dis 70: 1165-1167. http://doi.org/10.1136/ard.2010.137265.

Yang CY, Leung PS, Adamopoulos IE, Gershwin ME (2013) The implication of vitamin D and autoimmunity: a comprehensive review. Clin Rev Allergy Immunol 45: 217-26. http://doi.org/10.1007/s12016013-8361-3

Yusof MY, Emery P (2013) Targeting interleukin-6 in rheumatoid arthritis. Drugs 73: 341-56. http://doi.org/10.1007/s40265-013-0018-2 